\title{
Effect of the reaction temperature on the morphology of nanosized HAp
}

\author{
Szidónia György ${ }^{1,2} \cdot$ Zoltán Károly $^{1} \cdot$ Péter Fazekas $^{1} \cdot$ Péter Németh $^{1} \cdot$ Eszter Bódis $^{1} \cdot$ Alfréd Menyhárd $^{2} \cdot$ \\ László Kótai ${ }^{1} \cdot$ Szilvia Klébert ${ }^{1}$ [i]
}

Received: 29 October 2018/Accepted: 12 April 2019/Published online: 26 April 2019

(c) The Author(s) 2019

\begin{abstract}
We reported on the synthesis of nanosized hydroxyapatite particles by wet chemical precipitation method and the consolidation of the nanoparticles by spark plasma sintering. We studied the effect of the synthesis temperature on the particle size and phase composition of the obtained HAp. During synthesis beyond HAp, another phase supposedly nonstoichiometric HAp was also formed as a by-product that can be detected by thermal analysis combined with XRD. Its amount gradually decreased with the increase in synthesis temperature and practically disappeared at $80{ }^{\circ} \mathrm{C}$. Using this nanopowder for sintering, the spark plasma-sintered ceramics retained their nanostructure comprising only HAp phase in contrast to the powders synthesized at lower temperature when transformed products of the nonstoichiometric HAp could also be detected.
\end{abstract}

Keywords Hydroxyapatite $\cdot$ Spark plasma sintering $\cdot$ Crystallinity $\cdot$ Wet chemical precipitation $\cdot$ Nanopowder

\section{Introduction}

Hydroxyapatite (HAp) is one of the most widespread calcium phosphate due to its excellent characteristics. It is biocompatible, bioactive, osteoconductive and its chemical composition, namely $\mathrm{Ca} / \mathrm{P}$ ratio (1.67), is similar to the inorganic compound of bone; therefore, it is widely used as a bone substitute material [1]. Furthermore, because of the aforementioned properties HAp coatings on metal implants are frequently used in orthopedic surgery [2, 3]. Moreover, owing to its chemical and crystal structure it shows high capacity for ion exchange even with heavy metals [4]. A material exhibiting biodegradable properties could be a good candidate for drug delivery $[5,6]$ or cancer diagnosis

Szilvia Klébert

klebert.szilvia@ttk.mta.hu

1 Institute of Materials and Environmental Chemistry, Research Centre for Natural Sciences, Hungarian Academy of Sciences, Magyar tudósok krt 2, Budapest 1117, Hungary

2 Laboratory of Plastics and Rubber Technology, Department of Physical Chemistry and Materials Science, Budapest University of Technology and Economics, Budapest 1521, Hungary
$[7,8]$. Due to its complex interaction with biomacromolecules, it may serve as an ideal and cheap material in rapid bioseparation $[9,10]$. In addition, the size of the HAp grains or crystals, the exact chemical composition, morphology and crystallinity also influence its properties and hence the application fields $[11,12]$.

One of the greatest obstacles for widespread application of HAp implants is the poor strength and brittleness of the sintered materials. One approach to increase the strength of ceramics is to fabricate nanostructured material that possesses enhanced mechanical properties according to the well-known Hall-Petch relation. Moreover, nanobioceramics exhibit enhanced resorbability and higher bioactivity [13-15]. HAp ceramics prepared from nanosized HAp particles have been reported [16] to show apparently enhanced mechanical properties. As a result, several methods have been developed over the past few decades to prepare nanoparticles with well-defined shapes [14, 17] including wet chemical methods, dry methods, high-temperature or biogenic material-based methods and their combinations [14]. The various preparation methods have extensively been reviewed in the earlier literature $[14,18,19]$. 
The simplest and consequently the most frequently used synthesis method is precipitation, in which dissolved $\mathrm{Ca}^{2+}$ ions $\left(\mathrm{CaCl}_{2}\right.$, [20] $\mathrm{Ca}\left(\mathrm{NO}_{3}\right)_{2}$, [21] $\mathrm{Ca}(\mathrm{OH})_{2}$, [22] $\mathrm{CaCO}_{3}$, [23]) are reacted with $\mathrm{PO}_{4}{ }^{3-}\left(\mathrm{H}_{3} \mathrm{PO}_{4},\left(\mathrm{NH}_{4}\right)_{2} \mathrm{HPO}_{4}, \mathrm{NH}_{4-}\right.$ $\mathrm{H}_{2} \mathrm{PO}_{4}, \mathrm{Na}_{3} \mathrm{PO}_{4}$, and $\mathrm{KH}_{2} \mathrm{PO}_{4}$ ) ions in aqueous solution at $\mathrm{pH}$ over 9 . This procedure rapidly results in nanometric size HAp precipitates with high yield. The control of parameters influences the nature of the final product. Besides the desired product, nonstoichiometric and poorly crystalline HAp and other calcium phosphates could occur [24]. Eanes et al. [25] examined the effect of the reaction time and found that well-crystallized HAp formation takes at least $24 \mathrm{~h}$ at room temperature. They divided HAp formation into three stages. In the first five-hour long period only amorphous-like HAp forms followed by crystallization with concomitant decrease in the amorphous component. During the final, seven-hour long stage, the amorphous phase completely disappears. However, the reported formation mechanism was investigated only in room temperature conditions. Webster et al. [26] found that at $90{ }^{\circ} \mathrm{C}$ the formed HAp grain size was greater than at room temperature, but the products were not characterized by XRD. Similar conclusion was drawn by Liu et al. [27] for the particle size-investigated long-time reactions. Ishikawa et al. [28] found that peaks on XRD patterns of the precipitated HAp became sharper with increasing reaction temperatures indicating the higher crystallinity; however, the evaluation of XRD results was not complete in terms of phase identification.

Another crucial step of making porosity-free HAp ceramics is the selection of the proper sintering temperature. Even though higher temperature promotes the diffusion mechanisms of atoms and thus the consolidation of the powder, there is a risk of thermal decomposition of HAp, especially above $1200{ }^{\circ} \mathrm{C}$. The sintering temperature may be decreased using nanogranules having higher surface energy [29] and consequently greater sintering ability than its micron-sized counterparts [30]. By virtue of its unique sintering mechanism, spark plasma sintering (SPS) technique allows to achieve full density at considerably lower sintering temperature. In addition, due to the high heating rate (typically in the range of $100-200{ }^{\circ} \mathrm{C} \mathrm{min}{ }^{-1}$ ) characteristic for SPS, grain coarsening can be eliminated [31] and the sintered body preserves the nanostructure. Interestingly, in preliminary tests we realized that the SPSsintered specimens did not consist of pure HAp but occasionally contained other calcium phosphate phases, as well. The presence of unwanted by-products could result in decreased mechanical properties or inferior bioactivity [14] in medical applications [13, 32]. In most cases, optimization of synthesis condition is required to prepare a precursor powder, which can be adequately sintered preserving its phases and biological behavior after sintering.

In this work, we synthesized HAp nanoparticles by conventional wet chemical precipitation method and studied the effect of the synthesis temperature on the morphology of the synthesized particles as well as the spark plasma-sintered specimens.

\section{Materials and methods}

\section{Synthesis of hydroxyapatite nanopowder}

HAp nanoparticles were synthesized by precipitation method using calcium nitrate 4-hydrate $\left[\mathrm{Ca}\left(\mathrm{NO}_{3}\right)_{2} * 4\right.$ $\left.\mathrm{H}_{2} \mathrm{O}\right]$ and diammonium phosphate $\left[\left(\mathrm{NH}_{4}\right)_{2} \mathrm{HPO}_{4}\right]$ as calcium and phosphate sources, respectively. Chemicals were purchased from Szkarabeusz Laboratóriumi Ltd in analytical grade. The $\mathrm{pH}$ value of the reaction solution was maintained at 9.5 by adding $25 \% \quad \mathrm{NH}_{4} \mathrm{OH}$ (Reanal Laborvegyszer Kereskedelmi Ltd.) solution. HAp synthesis was performed at four different temperatures $\left(20^{\circ} \mathrm{C}\right.$, $40{ }^{\circ} \mathrm{C}, 60{ }^{\circ} \mathrm{C}$ and $80{ }^{\circ} \mathrm{C}$ ) using $8 \mathrm{~h}$ total stirring time in the particular tests. The obtained HAp precipitates were filtered, washed with distilled water and dried at $105^{\circ} \mathrm{C}$ for $24 \mathrm{~h}$. The dried products were ball-milled to a powdered form.

\section{Densification of HAp nanopowder}

The prepared powder was sintered to 3-mm-thick and 3-cm-diameter specimens by spark plasma sintering machine (HDP5, FCT $\mathrm{GmbH}$ ) at $900{ }^{\circ} \mathrm{C}$ with $5 \mathrm{~min}$ holding time. The applied heating rate was $100{ }^{\circ} \mathrm{C} \mathrm{min}-1$ between 25 and $800{ }^{\circ} \mathrm{C}$ that was lowered to $50{ }^{\circ} \mathrm{C} \mathrm{min}{ }^{-1}$ above $800{ }^{\circ} \mathrm{C}$. Temperature was continuously monitored by thermocouples inserted to the graphite die. A chamber pressure of $1 \mathrm{~atm}$ (Ar atmosphere) was maintained during consolidation. The powders were compressed uniaxially with $50 \mathrm{MPa}$ that was maintained throughout the sintering process. Linear shrinkage of the powder compacts was also monitored online by measuring the relative displacement of the graphite punch.

\section{Characterization of materials}

Apparent and bulk density of the sintered body was determined by Archimedes' principle immersion method. The phase compositions of the prepared powder and the sintered body were analyzed by a Philips PW 1830 X-ray diffractometer using $\mathrm{CuK} \alpha 1$ radiation in the range of $15-65^{\circ} 2 \theta$ with a step size of $0.04^{\circ}$. The morphology of synthesized powders and sintered body was characterized 
by scanning electronmicroscopy (SEM, Zeiss EVO40 XVP) and transmission electronmicroscopy (TEM, FEI Morgagni 268D). The thermal behavior of the powders was studied using PerkinElmer STA 6000 equipment. Both mass and heat flow signals were recorded, while samples were heated from room temperature $\left(25^{\circ} \mathrm{C}\right)$ to $900{ }^{\circ} \mathrm{C}$ at $10{ }^{\circ} \mathrm{C} \mathrm{min}^{-1}$ of heating rate. The experiments were carried out in $\mathrm{N}_{2}$ atmosphere, and the sample mass was approximately $5-7 \mathrm{mg}$.

\section{Results and discussion}

\section{Phase and structural analysis}

Figure 1 shows the X-ray powder diffraction patterns of HAp samples synthesized at different temperatures which exhibit apatite patterns with no extraneous peaks. It can be observed in Fig. 1 that FWHM (full width at half maximum) of the peaks decreases, i.e., peak become sharper with the increase in synthesis temperature. According to studies [25, 28, 33-36], peak broadening could be attributed either to decreased crystallinity or smaller crystallite size. Crystallite size calculation was performed using Scherrer equation [37] measuring the FWHMs of the diffraction peak at $2 \Theta=25.89$ corresponding to HAp $\{002\}$. The calculated crystallite size values are listed in Table 1.

Although a remarkable peak sharpening can be observed from 20 to $60{ }^{\circ} \mathrm{C}$, the crystallite size remained approximately the same $(\sim 20 \mathrm{~nm})$ for the samples prepared at 20 ,

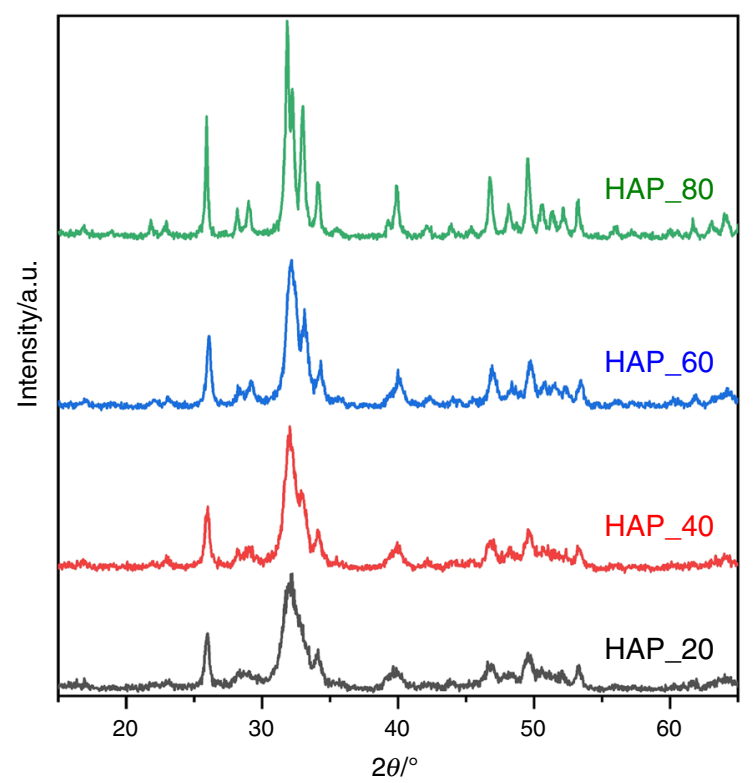

Fig. 1 X-ray powder diffraction patterns of hydroxyapatite powders prepared at various temperatures
40 and $60{ }^{\circ} \mathrm{C}$. It suggests that instead of changes in the crystallite size inadvertent formation of intermediate products during HAp preparation contributed to peak broadening. According to XRD database and the decomposition temperatures of calcium phosphates [38], we suppose that in addition to HAp, some kind of nonstoichiometric HAp was also formed during synthesis in the powders, which became more apparent in the samples synthesized at lower temperature. The formation of tricalcium orthophosphate hydrate $\left(\mathrm{Ca}_{3}\left(\mathrm{PO}_{4}\right)_{2} * \mathrm{H}_{2} \mathrm{O}\right.$, (JCPDS 18-0303) has been also reported during wet synthesis method of HAp, too. Later on, however, the existence of this material was refuted [39], which explains why its crystallographic parameters are still missing. A number of different nonstoichiometric HAp could also precipitate during preparation methods, and all of them have an X-ray pattern almost identical with HAp in spite of their different composition. The very small difference in lattice parameters owing to the presence of $\mathrm{HPO}_{4}^{2-}, \mathrm{H}_{2} \mathrm{PO}_{4}^{-}$or $\mathrm{CO}_{3}^{2-}$, $\mathrm{HCO}_{3}^{-}$and the concomitant $\mathrm{Ca}^{2+}$ deficiency would cause line broadening [40]. The identification of these compounds could be done by ${ }^{31} \mathrm{P}$ or ${ }^{1} \mathrm{H}$ NMR [41] and IR [45] when the phosphate (B site)/hydroxide ion (A site) substituting hydrogen phosphate or carbonate ion positions could also be distinguished. The estimated proportion of nonstoichiometric HAp and HAp in the synthesized powder is also listed in Table 1. Evaluation of the diffraction patterns have been obtained by full profile fitting techniques [42]. The content of nonstoichiometric HAp is rather high $(35 \%)$ in the sample prepared at $20^{\circ} \mathrm{C}$ but gradually decreases with increasing temperature. As a result, the apparently single broad peak between 32 and 35 $2^{\circ} \Theta$ splits into two peaks. The sample prepared at $80{ }^{\circ} \mathrm{C}$ practically contains only pure HAp. In order to find another evidence for the presence of the nonstoichiometric HAp, we performed heat treatment tests. The nonstoichiometric HAp which contains $\mathrm{CaHPO}_{4}$ in ionic form could react with HAp at elevated temperature and form $\alpha$-calcium phosphate (JCPDS C29-0359) and whitlockite (JCPDS 09-0169) with loss of a water molecule [39]. The as-formed phases serve as proof for the presence of nonstoichiometric HAp in the synthesized powder. This material could also be accounted for the contamination of some of the sintered HAp and thus could result in defective sintered body product [43]. In Fig. 2, we compared the XRD patterns of the powders synthesized at 20 and $80{ }^{\circ} \mathrm{C}$ as-prepared and after heat treatment at $800{ }^{\circ} \mathrm{C}$ for $2 \mathrm{~h}$. While no significant changes can be observed in the XRD patterns for test sample HAP_80, apparent changes occurred in the crystalline structure of sample HAp_20 on the effect of heat treatment. Peaks corresponding to HAp became sharper, while new peaks also appeared that can be assigned to 
Table 1 The crystallite sizes based on Scherrer equation and the estimated compositions of HAp powders synthesized at different temperatures

\begin{tabular}{lllll}
\hline Name & Synthesis temp/ ${ }^{\circ} \mathrm{C}$ & Crystallite size/nm & \multicolumn{2}{l}{ Estimated phase composition/mass\% } \\
\cline { 4 - 5 } & & & HAp & Nonstoichiometric HAp \\
\hline HAP_20 & 20 & 18 & 65 & $>35$ \\
HAP_40 & 40 & 20 & 75 & $<25$ \\
HAP_60 & 60 & 22 & 80 & $<20$ \\
HAP_80 & 80 & 50 & 98 & $<2$ \\
\hline
\end{tabular}

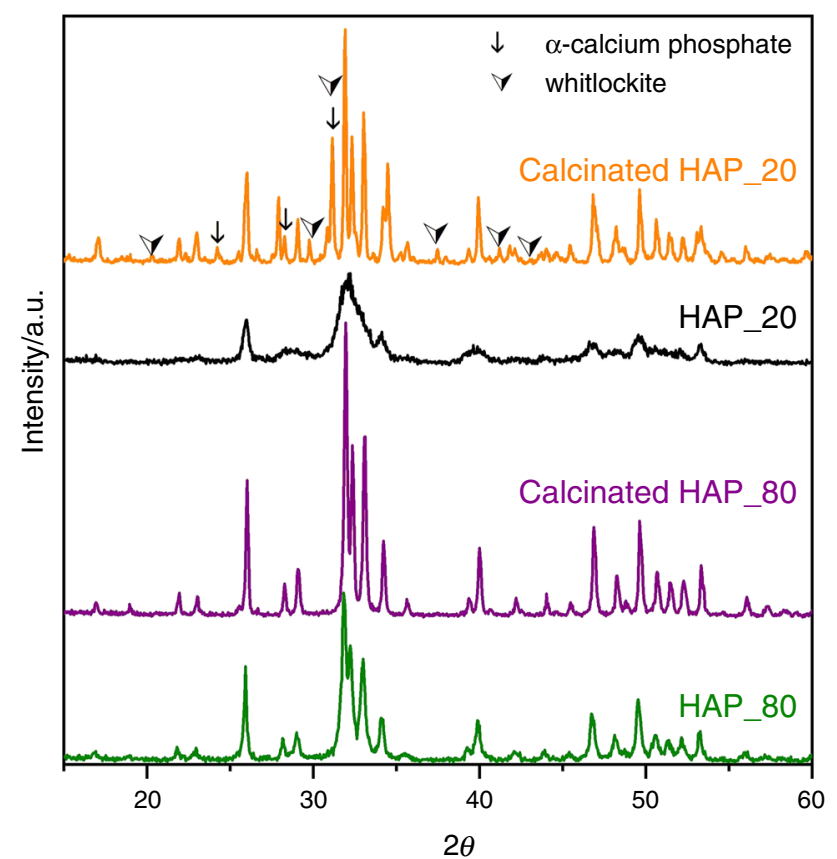

Fig. 2 X-ray powder diffraction patterns of HAp powders as synthesized at 20 and $80{ }^{\circ} \mathrm{C}$ and after calcination at $800{ }^{\circ} \mathrm{C}$

whitlockite and $\alpha$-calcium phosphate. All other unmarked peaks refer to HAp.

\section{Thermal analysis}

The presence of nonstoichiometric HAp was also investigated by thermal gravimetric analysis (TGA). TGA plots of the samples are illustrated in Fig. 3. A steeper decrease can be seen up to $200{ }^{\circ} \mathrm{C}$ followed by a slight one for each sample, both the decrease can be attributed to the elimination of adsorbed water from the surface. However, the sample prepared at $20{ }^{\circ} \mathrm{C}$ shows a small but sharp drop at $750{ }^{\circ} \mathrm{C}$ suggesting the reaction between dicalcium phosphate and HAp to form $\beta$-tricalcium orthophosphate namely whitlockite and at higher temperature further to form $\alpha$-tricalcium orthophosphate. The reaction accompanied the detachment of a water molecule that results in mass loss.

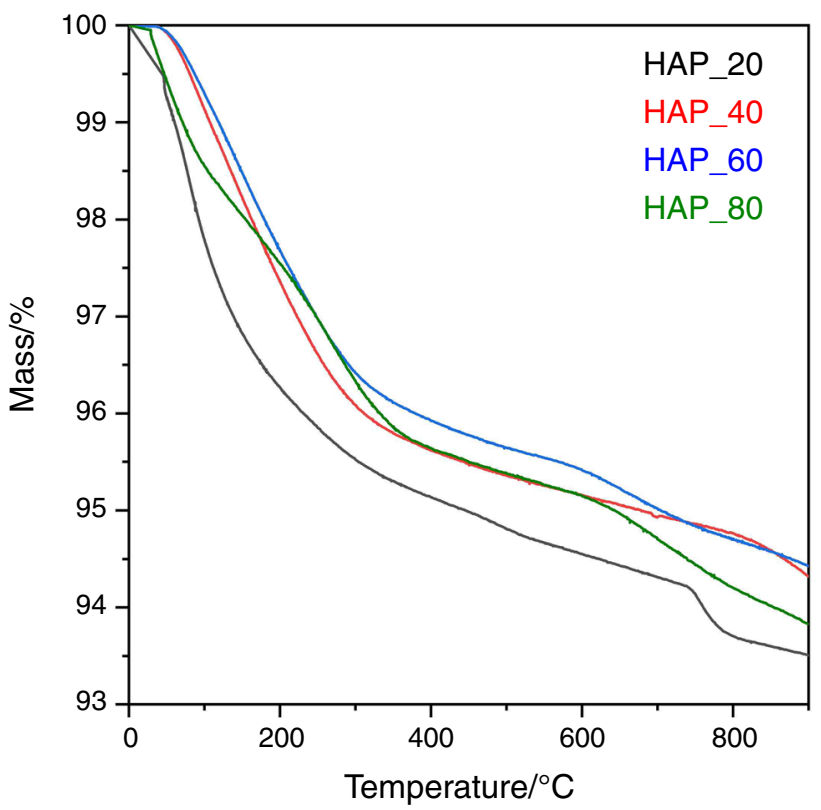

Fig. 3 TGA plots of hydroxyapatite powders synthesized at various temperatures

\section{TEM results}

TEM images were prepared to analyze the morphology and particle size of the synthesized powders as well as to determine their crystal structure. Figure 4 shows typical TEM images of the powder for each test sample and the corresponding diffraction pattern.

At $20{ }^{\circ} \mathrm{C}$, most of the particles are smaller than $20 \mathrm{~nm}$ (Fig. 4, HAP_20), which means that at low temperature there is not enough driving force for ripening of the crystals. On the effect of increased reaction temperature, crystals start to grow, which is in agreement with the XRD data (Table 1), and resemble the typical acicular shape of HAp. Electron diffraction patterns of the sample show the characteristic HAp ring pattern, which is indicative for nanocrystals. Since the error of the $d$ value measurement is larger than the $d$ value difference between HAp and nonstoichiometric HAp, the latter cannot be positively identified. 
Fig. 4 TEM images of nanoHAp powders synthesized at different temperatures

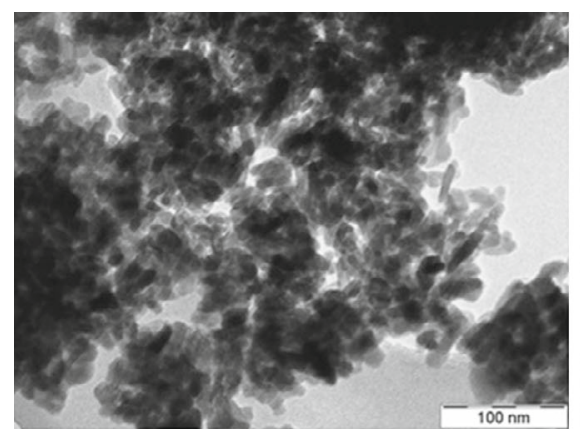

HAP_20

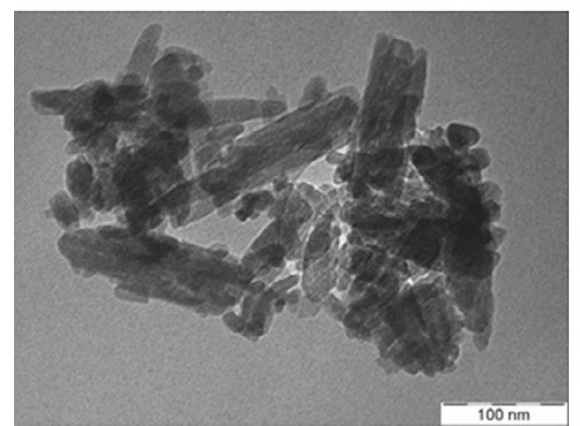

HAP_60

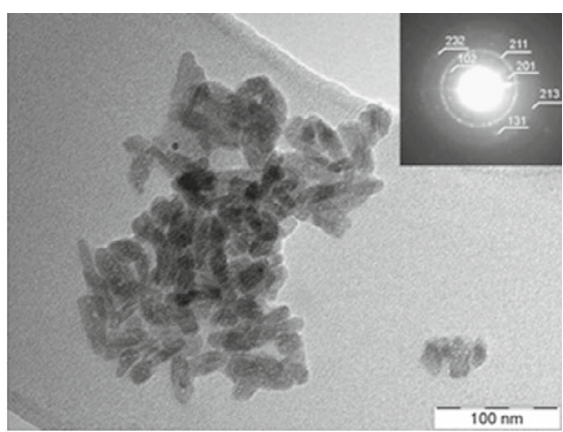

HAP_40

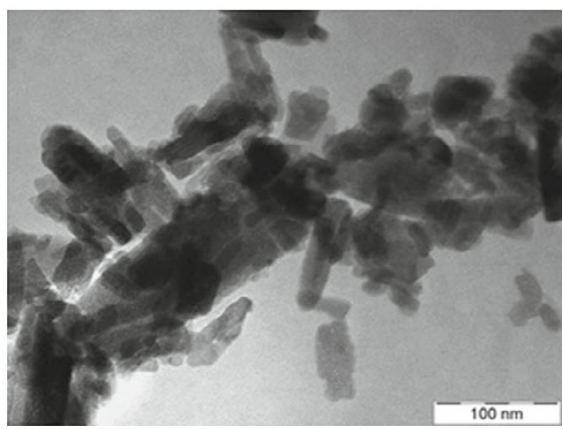

HAP_80

\section{Morphological study of sintered body}

Figure 5 shows characteristic curves of sintering including displacement, i.e., shrinkage of the powder, the sintering speed and the temperature in the function of sintering time. Although the sintering temperature was $900{ }^{\circ} \mathrm{C}$, the shrinkage rate suggests that sintering starts even at around $800{ }^{\circ} \mathrm{C}$. The heating rate was decreased, in agreement with our earlier work [44], as most of the shrinkage takes place between 800 and $900{ }^{\circ} \mathrm{C}$. The peak observed below this

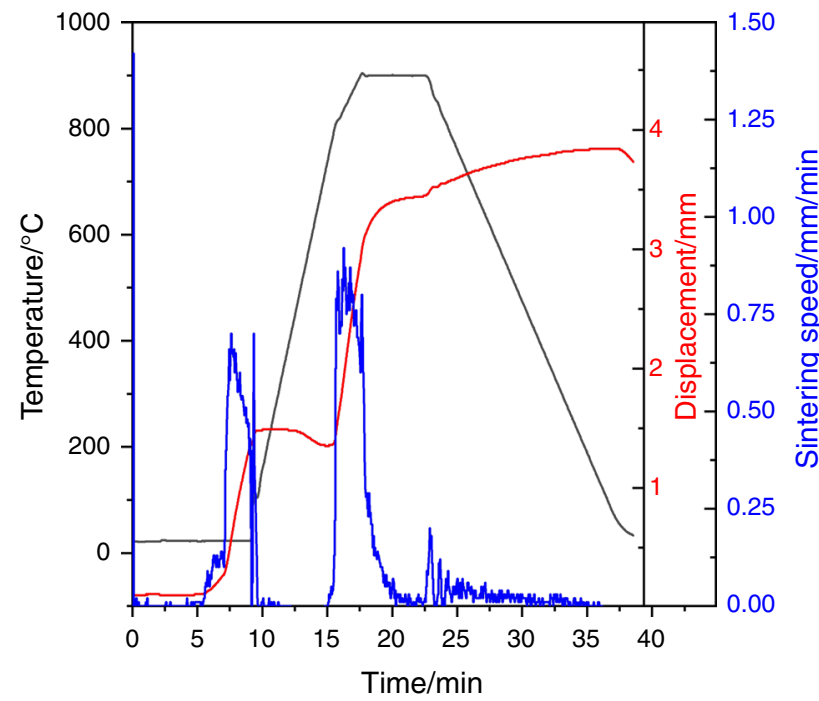

Fig. 5 Characteristic curves of the sintering of nano-HAp (HAP_80) in the function of time temperature corresponds to the compaction resulted from the increasing compression.

On the XRD pattern of the sintered HAp sample (Fig. 6), all the peaks can be assigned to HAp and no signs for other calcium phosphate by-products could be detected. The characteristic peaks are quite sharp, which suggests good crystallinity. The average crystallite size was of $197 \mathrm{~nm}$ calculated by Scherrer equation, whose value although higher than the crystalline size of HAp

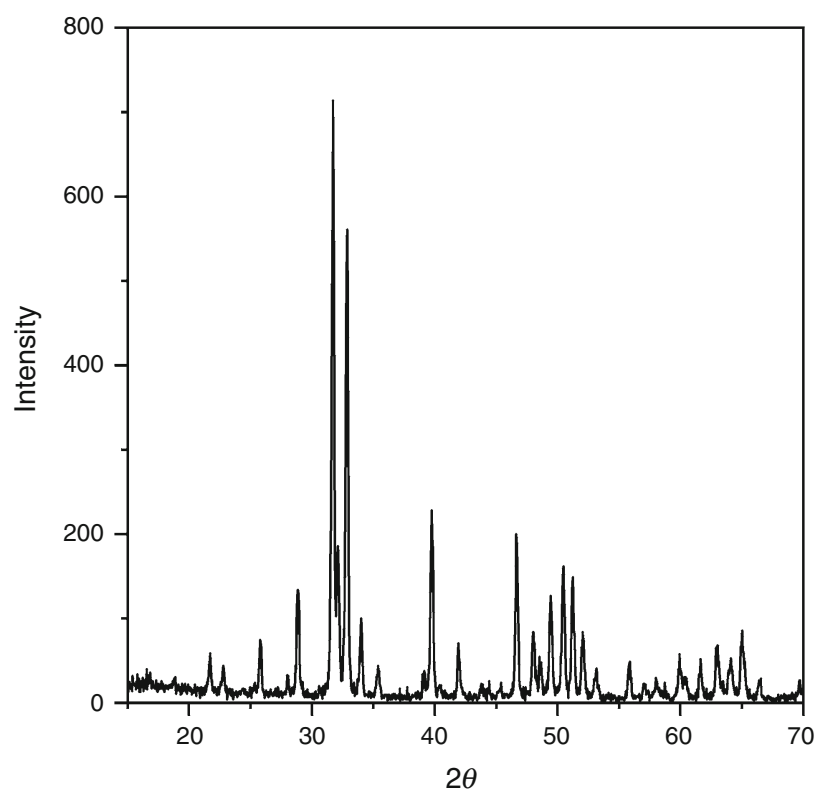

Fig. 6 X-ray diffraction pattern of sintered HAp sample 


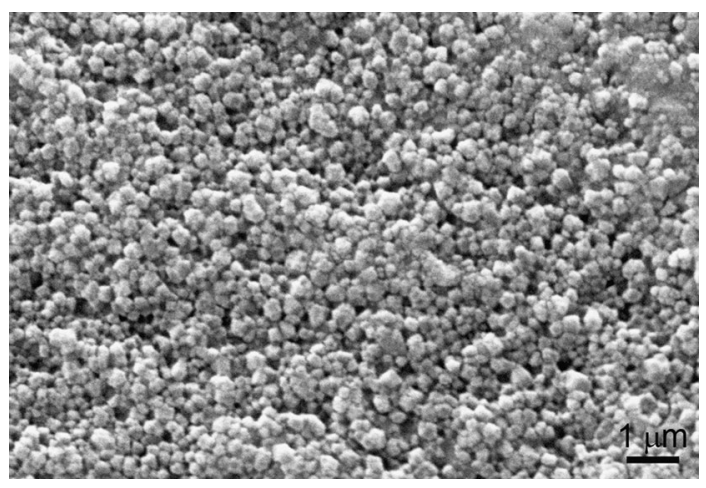

Fig. 7 SEM image of sintered HAp

synthesized at $80{ }^{\circ} \mathrm{C}$ is still well under micrometric size and can be considered as nanostructure. It shows that the rapid heating characteristic of SPS mechanism accompanied with the nanosized primary particles with greater activity for sintering altogether promoted to achieve a nanostructured bulk material. Figure 7 shows an image of the microstructure of sintered HAp that consists of hexagonal crystals with relative density of $97.82 \%$.

\section{Conclusions}

We synthesized nanometric sized hydroxyapatite powder by wet chemical precipitation at various temperatures ranging from 20 to $80{ }^{\circ} \mathrm{C}$. The prepared powders were used as precursors for SPS sintering. We concluded that precipitated particles were of nanometric size regardless of the synthesis temperature. Between 20 and $60{ }^{\circ} \mathrm{C}$, the particle size was around $20 \mathrm{~nm}$, while at $80{ }^{\circ} \mathrm{C}$ it increased to $50 \mathrm{~nm}$. The synthesis resulted in HAp as major constituent; however, another calcium phosphate phase supposedly nonstoichiometric HAp was also formed. Even though that phase can be hardly distinguished directly from HAp by $\mathrm{XRD}$, we could infer its presence by thermal analysis. Its amount was the highest at the lowest synthesis temperature and gradually decreased with the increase in temperature and completely disappeared in the sample prepared at $80{ }^{\circ} \mathrm{C}$. Using the impurity-free particles synthesized at $80{ }^{\circ} \mathrm{C}$ for the SPS sintering, we could fabricate specimen comprising pure HAp phase and retain the nanostructure in the sintered material. This result suggests that nanosized HAp particles prepared by precipitation should be synthesized at $80{ }^{\circ} \mathrm{C}$ to prevent decomposition and/or contamination of sintered HAp ceramics.

Acknowledgements Open access funding provided by MTA Research Centre for Natural Sciences (MTA TTK).

Open Access This article is distributed under the terms of the Creative Commons Attribution 4.0 International License (http:// creativecommons.org/licenses/by/4.0/), which permits unrestricted use, distribution, and reproduction in any medium, provided you give appropriate credit to the original author(s) and the source, provide a link to the Creative Commons license, and indicate if changes were made.

\section{References}

1. Vallet-Regí M, González-Calbet JM. Calcium phosphates as substitution of bone tissues. Prog Solid State. 2004;32:1-31.

2. Habibovic P, Barrère F, Blitterswijk CA, Groot K, Layrolle P. Biomimetic hydroxyapatite coating on metal implants. J Am Ceram Soc. 2004;85:517-22.

3. Bogya ES, Károly Z, Barabás R. Atmospheric plasma sprayed silica-hydroxyapatite coatings on magnesium alloy substrates. Ceram Int. 2015;41:6005-12.

4. Reichert J, Binner JGP. An evaluation of hydroxyapatite-based filters for removal of heavy metal ions from aqueous solutions. J Mater Sci. 1996;31:1231-41.

5. Mondal S, Dorozhkin SV, Pal U. Recent progress on fabrication and drug delivery applications of nanostructured hydroxyapatite. Wiley Interdiscip Rev Nanomed Nanobiotechnol. 2017;10:e1504.

6. Yu D, Wong J, Matsuda Y, Fox JL, Higuchi WI, Otsuka M. Selfsetting hydroxyapatite cement: a novel skeletal drug-delivery system for antibiotics. J Pharm Sci. 1992;81:529-31.

7. Sun W, Fan J, Wang S, Kang Y, Du J, Peng X. Biodegradable drug-loaded hydroxyapatite nanotherapeutic agent for targeted drug release in tumors. ACS Appl Mater Interfaces. 2018;10:7832-40. https://doi.org/10.1021/acsami.7b19281.

8. Bauer IW, Li S-P, Han Y-C, Yuan L, Yin M-Z. Internalization of hydroxyapatite nanoparticles in liver cancer cells. J Mater Sci Mater Med. 2008;19:1091-5.

9. Hilbrig F, Freitag R. Isolation and purification of recombinant proteins, antibodies and plasmid DNA with hydroxyapatite chromatography. Biotechnol J. 2012;7:90-102.

10. Niimi M, Masuda T, Kaihatsu K, Kato N, Nakamura S, Nakaya $\mathrm{T}$, et al. Virus purification and enrichment by hydroxyapatite chromatography on a chip. Sens Actuators B Chem. 2014;201:185-90.

11. Roveri N, Iafisco M. Evolving application of biomimetic nanostructured hydroxyapatite. Nanotechnol Sci Appl. 2010;3:107-25.

12. Balasundaram G, Sato M, Webster TJ. Using hydroxyapatite nanoparticles and decreased crystallinity to promote osteoblast adhesion similar to functionalizing with RGD. Biomaterials. 2006;27:2798-805.

13. Cai Y, Liu Y, Yan W, Hu Q, Tao J, Zhang M, et al. Role of hydroxyapatite nanoparticle size in bone cell proliferation. J Mater Chem. 2007;17:3780.

14. Sadat-Shojai M, Khorasani M-T, Dinpanah-Khoshdargi E, Jamshidi A. Synthesis methods for nanosized hydroxyapatite with diverse structures. Acta Biomater. 2013;9:7591-621.

15. Dorozhkin SV. Nanosized and nanocrystalline calcium orthophosphates. Acta Biomater. 2010;6:715-34.

16. Wang J, Shaw LL. Nanocrystalline hydroxyapatite with simultaneous enhancements in hardness and toughness. Biomaterials. 2009;30:6565-72.

17. Wijesinghe WPSL, Mantilaka MMMGPG, Premalal EVA, Herath HMTU, Mahalingam S, Edirisinghe M, et al. Facile synthesis of both needle-like and spherical hydroxyapatite nanoparticles: effect of synthetic temperature and calcination on morphology, crystallite size and crystallinity. Mater Sci Eng C. 2014;42:83-90. 
18. Ferraz MP, Monteiro FJ, Manuel CM. Hydroxyapatite nanoparticles: a review of preparation methodologies. J Appl Biomater Funct Mater. 2014;2:74-80.

19. Orlovskii VP, Komlev VS, Barinov SM. Hydroxyapatite and hydroxyapatite-based ceramics. Inorg Mater. 2002;38:973-84.

20. Eiden-Aßmann S, Viertelhaus M, Heiß A, Hoetzer K, Felsche J. The influence of amino acids on the biomineralization of hydroxyapatite in gelatin. J Inorg Biochem. 2002;91:481-6.

21. Pelin IM, Maier SS, Chitanu GC, Bulacovschi V. Preparation and characterization of a hydroxyapatite-collagen composite as component for injectable bone substitute. Mater Sci Eng, C. 2009;29:2188-94.

22. Guo X, Xiao P, Liu J, Shen Z. Fabrication of nanostructured hydroxyapatite via hydrothermal synthesis and spark plasma sintering. J Am Ceram Soc. 2005;88:1026-9.

23. Siva Rama Krishna D, Siddharthan A, Seshadri SK, Sampath Kumar TS. A novel route for synthesis of nanocrystalline hydroxyapatite from eggshell waste. J Mater Sci Mater Med. 2007; 18:1735-43.

24. Kumta PN, Sfeir C, Lee D-H, Olton D, Choi D. Nanostructured calcium phosphates for biomedical applications: novel synthesis and characterization. Acta Biomater. 2005;1:65-83.

25. Eanes ED, Gillessen IH, Posner AS. Intermediate states in the precipitation of hydroxyapatite. Nature. 1965;208:365-7.

26. Webster TJ, Ergun C, Doremus RH, Siegel RW, Bizios R. Enhanced functions of osteoblasts on nanophase ceramics. Biomaterials. 2000;21:1803-10.

27. Liu C, Huang Y, Shen W, Cui J. Kinetics of hydroxyapatite precipitation at $\mathrm{pH} 10$ to 11 . Biomaterials. 2001;22:301-6.

28. Ishikawa K, Kon M, Tenshin S, Kuwayama N. Effects of preparation conditions in aqueous solution on properties of hydroxyapatites. Dent Mater J. 1990;9(58-69):123.

29. Nanda KK, Maisels A, Kruis FE, Fissan H, Stappert S. Higher surface energy of free nanoparticles. Phys Rev Lett. 2003;91:106102.

30. Lu K. Sintering of nanoceramics. Int Mater Rev. 2008;53:21-38.

31. Gu YW, Loh NH, Khor KA, Tor SB, Cheang P. Spark plasma sintering of hydroxyapatite powders. Biomaterials. 2002;23:37-43.

32. Li L, Liu Y, Tao J, Zhang M, Pan H, Xu X, Tang R. Surface modification of hydroxyapatite nanocrystallite by a small amount of terbium provides a biocompatible fluorescent probe. J Phys Chem C. 2008;112:12219-24.
33. Fathi MH, Hanifi A, Mortazavi V. Preparation and bioactivity evaluation of bone-like hydroxyapatite nanopowder. J Mater Process Technol. 2008;202:536-42.

34. Pang $Y X, B a o X$. Influence of temperature, ripening time and calcination on the morphology and crystallinity of hydroxyapatite nanoparticles. J Eur Ceram Soc. 2003;23:1697-704.

35. Bouyer E, Gitzhofer F, Boulos MI. Morphological study of hydroxyapatite nanocrystal suspension. J Mater Sci Mater Med. 2000;11:523-31.

36. Aoba T, Moreno EC. Preparation of hydroxyapatite crystals and their behavior as seeds for crystal growth. J Dent Res. 1984;63:874-80.

37. Jenkins R, Snyder RL. Introduction to X-ray powder diffractometry. London: Wiley; 1996.

38. Mclntosh AO, Jablonski WL. X-ray diffraction powder patterns of the calcium phosphates. Anal Chem. 1952;28:1424-7.

39. Gee A, Deitz VR. Pyrophosphate formation upon ignition of precipitated basic calcium phosphates. J Am Chem Soc. 1955;77:2961-5.

40. Eisenberger S, Lehrman A, Turner WD. The basic calcium phosphates and related systems. Some theoretical and practical aspects. Chem Rev. 1940;26:257-96.

41. Rothwell WP, Waugh JS, Yesinowsk JP. High-resolution variable-temperature ${ }^{31} \mathrm{P}$ NMR of solid calcium phosphates. J Am Chem Soc. 1980;102:2637-43.

42. Kótai L, Pasinszki T, Zs Czégény, Sz Bálint, Sajó I, May Z, Németh P, Károly Z, Sharma PK, Sharma V, Banerji KK. Metal and metal-sulphide containing carbons from sulphonated styrenedivinylbenzene copolymer based ion-exchangers. Eur Chem Bull. 2012;1:398-400.

43. Koerten HK, van der Meulen J. Degradation of calcium phosphate ceramics. J Biomed Mater Res. 1999;44:78-86.

44. Klébert S, Balázsi C, Balázsi K, Bódis E, Fazekas P, Keszler AM, et al. Spark plasma sintering of graphene reinforced hydroxyapatite composites. Ceram Int. 2015;41:3647-52.

45. Koutsopoulos S. Synthesis and characterization of hydroxyapatite crystals: a review study on the analytical methods. J Biomed Mater Res. 2002;62:600-12.

Publisher's Note Springer Nature remains neutral with regard to jurisdictional claims in published maps and institutional affiliations. 